\title{
OS ESCRITOS CRÍTICOS E POLÍTICOS EM MEMÓRIA POR CORRESPONDÊNCIA (2016), DE EMMA REYES
}

\section{[Emma Reyes' Critical and Political Writings in Emma Reyes' Memoir by Correspondence (2016)]}

\author{
Christine Gryschek ${ }^{1}$ \\ Altair Teixeira Martins ${ }^{2}$
}

\begin{abstract}
RESUMO: Memória por correspondência (2016), romance epistolar no qual encontram-se reunidas vinte e três cartas escritas por Emma Reyes (1919-2003), expõe uma tentativa de reconstrução e apresentação de um passado em um registro externo. Mas nos traz, antes de uma narrativa íntima, um retrato de uma sociedade colonizada católica e repartida em classes. Neste sentido, as memórias são, além de uma reconexão com seu processo de subjetivação, repletas de críticas políticas nas quais a narradora não economiza questionamentos e reflexões importantes a respeito do estado e da religião. Tal característica coloca a escrita de Reyes como Literatura Menor. O texto é de denúncia ao modelo de sociedade empregada por modelos tradicionalistas de um poder pastoral e as chamadas Instituições Totais, apresentando os detalhes das normas e das condutas disciplinares os quais foi obrigada a desempenhar durante seu crescimento e constituição de subjetividade, dentro do convento onde viveu a sua infância em sofrimento. Palavras-chave: Processo de Subjetivação; Subjetividade; Literatura Menor; Poder Pastoral; Instituição Total.
\end{abstract}

ABSTRACT: The book of Emma Reyes: A memoir in correspondence (2016), is an epistolary novel in which are gathered twenty three letters written by the visual artist Emma Reyes (1919-2003) and it exposes an attempt to rebuild and present her past in an external record. However, it brings us, besides an intimate narrative, a portrait of a colonized catholic society, distributed in classes. In this sense, her memories are not only a reconnection with her process of subjectivation, but are filled with political criticism which do not spare important questions and observations about the state and the religion. This characteristic makes Reyes' writing as Literature Minor. Her text is a denunciation on the model of society employed by the traditions of a Pastoral Power and of the so-called Total Institutions showing the details of the norms and disciplinary conducts imposed on her during her growth and subjectivation constitution, inside a convent where she lived in suffering during her childhood.

Keywords: Subjectivation Process; Subjectivity; Minor Literature; Pastoral Power; Total Institution.

1 Mestranda em Escrita Criativa - PPGL (Pucrs) e em Psicologia Social e Institucional - PPGPSI (UFRGS). E-mail: christinegryschek@gmail.com

2 Professor da Faculdade de Letras e de Escrita Criativa da Pontifícia Universidade Católica do Rio Grande do Sul (PUCRS), atuando no Programa de Pós-graduação. 


\section{ESCRITA VIVA}

Memória por correspondência (2016) é um romance epistolar no qual se encontram reunidas vinte e três cartas escritas pela artista visual Emma Reyes (1919-2003) para seu amigo Germán Arciniegas, durante um período de aproximadamente 30 anos (1969-1997). As vinte e três cartas reunidas contam a infância de Emma, com detalhes preciosos, em uma tentativa de reconstrução e apresentação do seu passado em um registro externo, para além das lembranças carregadas em sua cabeça. Emma configura sua narrativa como uma escrita modelável, em que os traços de dureza são associados a pontos delicados e ao seu senso de humor. Assim, a escritora constrói para seu amigo, e depois para os demais leitores, um retrato seu quando criança, em um recorte específico de sua vida e experiências na Colômbia além de, em conjunto, apresentar o funcionamento de instituições sociais. Portanto, Memória por Correspondência (2016) é, antes de uma narrativa íntima, um retrato de uma sociedade colonizada católica e repartida em classes. As memórias estão repletas de críticas políticas nas quais a personagem Emma não economiza questionamentos e reflexões importantes a respeito do estado e da religião (Católica Apostólica Romana).

Deve lhe parecer estranho que eu consiga relatar com tantos detalhes e com tamanha precisão acontecimentos de uma época tão distante. Assim como você, também acho que uma criança de cinco anos que leva uma vida normal não conseguiria reproduzir a própria infância com a mesma fidelidade (...) nada nos escapava: nem gestos, nem palavras, nem ruídos, nem cores; tudo estava claro para nós. (REYES, 2016, p. 70)

Emma detalha como se a memória estivesse viva, traz em suas cartas confecções de uma infância presente em excesso, em uma escrita impregnada realidade. Neste sentido, coloco que "escrever é herdar um mundo com todas as suas fossilizações" (COSTA, 2017, p. 58), escrever é estar atento ao regime do tempo, é partilhar sensivelmente. Escrever é atuar entendendo que não existe ato sem significação e, ao mesmo tempo, é criar uma relação da mão que traça signos com o corpo que ela estende e dilata, uma relação do corpo com a alma que traz o ânimo e com os outros corpos que compartilham vivências; criar uma relação também dessa comunidade com sua alma (RANCIÉRE, 1995, p. 7). A artista conjuga o verbo escrever de modo primoroso, elegante e magistral, partilhando os afetos, as afecções e as reflexões adquiridas ainda enquanto criança. Relembro o que Gagnebin nos destaca: a escrita tem sido por muito tempo o rastro de maior duração que as pessoas podem deixar (2006, p. 114). Associo que a escrita de Emma, enquanto rastro, mostra as marcas que ressignificam a narrativa de sua vida (GAGNEBIN, 2006, p. 114), e escancara o marco abjeto, a descrição dos traumas, do corpo que relata mesmo em dano, do corpo que adoece, do corpo doente ou danificado que é a base evidencial de um importante e necessário testemunho contra o poder (FOSTER, 2014, p. 79), testemunho este que nos oportuniza um exercício da política de alteridade (ibid., p. 79). Exemplifico com um fragmento do relato contido ao final da carta quatro: “(...) a cara grudada no chão. Acho que, neste instante, de uma tacada só, aprendi o que é injustiça e descobri que uma criança de quatro anos já pode 
sentir vontade de não querer mais viver e ser devorada pelas entranhas da terra" (REYES, 2016, p. 58). Este exemplo nos traz um corpo que fala de política com o próprio corpo, um corpo vivo, furtivo, pulsional, um corpo próprio, um corpo único (BARTHES, 2003, p. 193). "Perdi toda a resistência, estendi-lhe a mão, ela me pegou nos braços e começou a correr feito louca. Apertava-me com toda a força contra o corpo, quase sem respirar (...) Só parou ao alcançar a ponte" (REYES, 2016, p. 58). A escrita de Emma é uma escrita que passa pelo corpo, a escrita de um corpo que se expressa, de um corpo que conta, que surpreende e que decide. Escrita de um corpo-máquina de expressão que desorganiza as próprias formas, que desorganiza os conteúdos e que, com isso, marca as rupturas e derivações que daí nascem; as formas quebradas reconstituem outro conteúdo que estará (necessariamente) em ruptura com a ordem das coisas (DELEUZE; GUATTARI, 2003, p. 57-58). E Emma concentra forças para aproximar-se do "excesso de realidade vivido" (ANTONELLO; GONDAR, 2014, p.100), cria um lugar para o irrepresentável ao conseguir escrever as suas próprias desgraças, transformando-as em linguagem (ibid., p. 102). A linguagem advinda do testemunho de Emma é configurada como uma linguagem do sensível, como uma linguagem literal, invocativa, ardente, criativa, invocada diretamente dos signos de percepção (ibid., p. 102). As cartas escritas se traduzem em um testemunho, uma tessitura narratológica implicada em um processo no qual a artista está assumindo uma nova posição subjetiva, não apenas reproduzindo o que foi traumático, mas configurando um processo criativo (ibid., p. 100).

Figura 1 Bram VanVelde, Emma Reyes

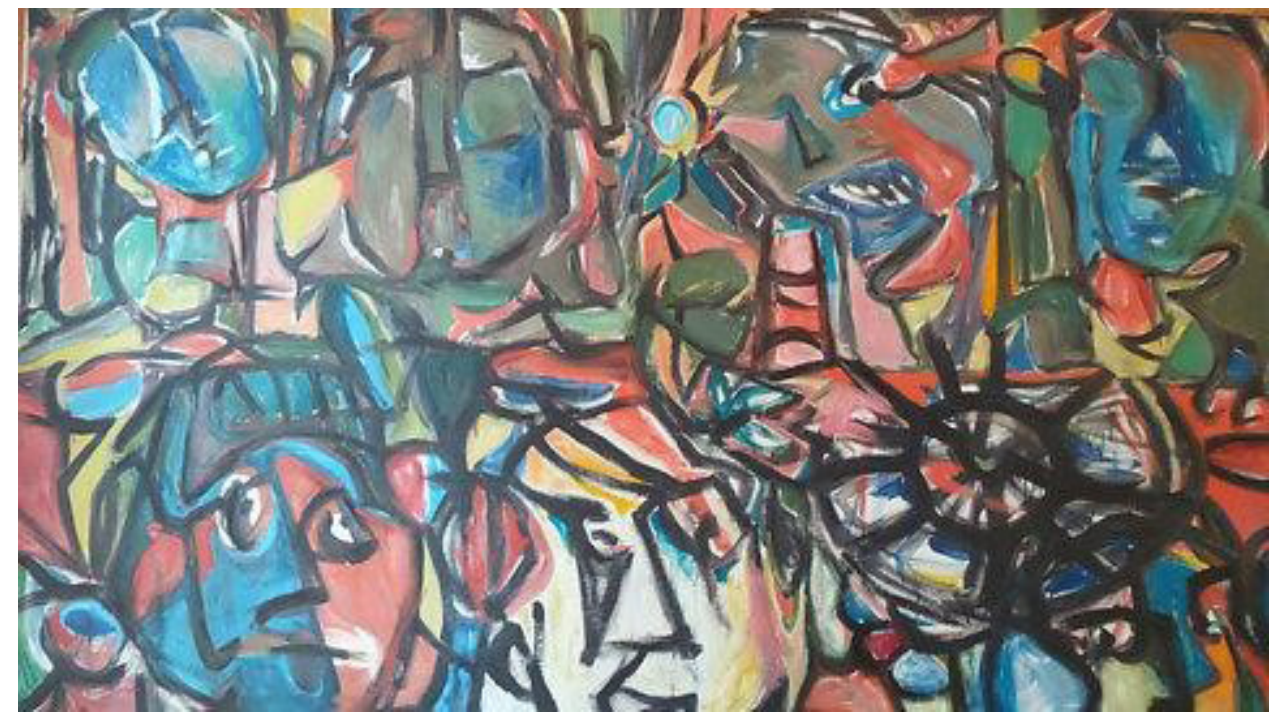

Fonte: http://www.emma-reyes.com/albums/periode-3/. Acesso em 18/ 05/ 2020

\section{REALIDADE RELATADA}

A partilha da artista está implicada no que podemos classificar enquanto seu processo de subjetivação. Falamos, assim, do plano em que o processo da construção de si ocorre. Durante a leitura das vinte e três cartas, este processo é verificado de forma ampla em dois momentos: o primeiro é quando compreendemos que a autora passou por uma movimen- 
tação de subjetividade em sua vida além-páginas, na qual se desenvolveu e se constituiu enquanto sujeito; e o segundo é resultado de suas rememorações através do acionamento das memórias, na reconstrução das vivências e dos fatos. É na escrita de seu testemunho, no ato da escrita, da criação de sua linguagem, que Reyes destaca suas experiências e reafirma as suas memórias, recontando para si e contando para o mundo como foi que se constituiu pessoa e quais foram os acontecimentos e desacontecimentos de sua história. Também conta por quais razões se acometeu, quais escolhas forçosamente realizou, e quais os medos e privações que a assolaram.

Assim, um processo de subjetivação está narrado nas páginas de Memória por correspondência (2006). Retomo colocando que a narrativa traumática, a narrativa de testemunho, a narrativa íntima política da artista, nos oferece a leitura de um processo de crescimento, de formação, de fatores que contribuíram com força para a formação de sua subjetividade. Por subjetividade entendemos, dentro da perspectiva pós-estruturalista, a constitutiva de um sujeito que "está sempre por se fazer" (HENNIGEN; GUARESCHI, 2006, p. 66). Tal sujeito (aqui retomo o nome "Emma Reyes") “é visto como derivado de práticas sociais, econômicas, culturais, políticas." (ibid., p. 66), "O sujeito não faz história, mas antes é construído pela mesma, de variadas formas, em diferentes épocas” (ibid., p. 66). O sujeito “(...) é um efeito das práticas de significação” (ibid., p. 66). A compreensão de Foucault sobre essa subjetividade à qual o sujeito se modela é trazida por Hennigen e Guareschi como " (...) modo no qual o sujeito faz a experiência de si mesmo num jogo de verdade em que ele está em relação consigo mesmo" (2006, p. 66). Uma subjetividade que trata “(...) de uma consciência de si permanentemente em produção, uma formação existencial constituída em um determinado tempo-espaço" (ibid., p. 66). Finalmente, a ideia de processo de subjetivação pode ser definida como “(...) aquilo que está sendo permanentemente constituído culturalmente" (ibid., p. 66). Processo que envolve um "modo de vida" no qual o sujeito é constituído por meio da história e do tempo e pela relação que tem com as coisas. Também vai sendo constituído pelas relações, “ (...) compreendendo todas as práticas que envolvem o cuidado de si" (FREITAS; SILVEIRA; MASCIA, 2017, p. 581), "ora como extensão do cuidado com o outro", (ibid., p. 581), "ora como cuidado de si para si mesmo” (ibid., 2017, p. 581). Finalmente, “(...) para Foucault, o sujeito vai sendo constituído, ele não existe a priori. A constituição do sujeito depende das relações de poder às quais está submetido em um determinado momento histórico" (ibid., p. 581). Isto é demonstrado em cada acontecimento narrado, em cada observação feita pela criança Emma. Sentimos na narrativa alguém que está sempre em relação, observando e sendo observada, seja por instituições, seja por medos, seja por pessoas. E é tão forte no livro a questão relacional que transcrevo uma passagem bastante significativa:

Fomos chamadas de Novas por mais de um ano até o dia em que chegou outra Nova e imediatamente recuperamos nossos nomes. Já estávamos nos acostumando, mas o fato de nos chamarem como a sra. María e Betzabé nos mudou completamente. Eu comecei a ganhar coragem para me afastar de Helena e conversar com outras meninas. (REYES, 2016, p. 114)

Emma estabelece elos de vida com o meio circundante, constituindo e sendo constituída pela própria rede, sendo sujeito-mundo, estando em relação de troca e produção 
(TEDESCO, 2006, p. 361). A identidade, a subjetividade da autora-personagem, se refere principalmente às relações, a rede de conexões que a constituíram (ibid., p. 358).

Temos em Memória por correspondência (2016) um documento valioso para uma análise de subjetividade porque Emma não oferece uma personagem constituída de verdade de si, autêntica em si mesma, mas apresenta antes e constantemente, “(...) a construção móvel, fluída e nômade" (IONTA, 2011, p. 99). Encontramos, assim, uma personagem que avalia suas ações e pensamentos, e que registra um estatuto ético e estético da fabricação de si mesma (ibid., p. 99). Encontramos nesta narrativa uma literatura que “ (...) pode ser tão transgressiva quanto aquela que visa transpor o limite da linguagem” (ibid., p. 94), porque “(...) trata-se de um se reinventar a si mesma na e pela escrita cotidiana” (ibid., p. 94). Na literatura de si, encontrada nas cartas pessoais (aqui, em Emma), percebemos uma lupa subjetiva, percebemos epístolas “(...) tingidas pela reflexão, introspecção, interioridade, intimidade” (ibid., p. 93). Percebemos uma escrita que “(...) tensiona as fronteiras exibição / contenção, presença / ausência, proximidade / distância, fala / escrita, realidade / ficção, dentro / fora" (ibid., p. 93). Ainda: insisto no papel ímpar das epístolas redigidas: é possível “(...) visualizar vetores que conjugam simultaneamente movimentos de desprendimento de si e auto elaboração" (ibid., p. 94), visto que capturam instantes fugidios e processos de metamorfose pessoal (ibid., p. 94).

E não me repreenda, porque se você acredita que basta ter ideias, lhes digo que se a gente não sabe escrevê-las de modo que sejam compreensíveis, é como se não as tivesse. Minha cabeça é um quarto abarrotado de trates velhos que nem sei mais o que são nem em que estado se encontram. (REYES, 2016, p. 103)

\section{DENTRO E FORA}

Ao contar-se e contar o meio que a circunda, denunciando-o e contrapondo-o, a autora participa de uma Literatura Menor. Pois considera-se, em termos de Literatura Menor, que as questões individuais estão diretamente relacionadas às questões políticas. "A questão individual, ampliada ao microscópio, torna-se muito mais necessária, indispensável, porque uma outra história se agita em seu interior" (DELEUZE; GUATTARI, 2003, p. 40). Vemos na Literatura Menor de Reyes, um enunciado contaminado pelo campo político (ibid., p. 40). Vemos presentes no texto as três categorias de uma Literatura Menor: "a desterritorialização da língua, a ligação do individual com o imediato político, o agenciamento coletivo de enunciação" (ibid., p. 40). Este dispositivo colocado pelos autores como menor é corrosivo, desafia politicamente e provoca uma "dissonância no modo de ser e estar dos indivíduos em sociedade" (IONTA, 2011, p. 94). Verificamos uma Literatura Menor em Emma também pelo fato da autora "estar a margem em relação a modelos canônicos" (BATALHA, 2014, p. 116). As características principais dos textos colocados como tradicionais, fecundados e canonizados são a linearidade, cadeia e evolução textual (ibid., p. 120). Já o trabalho de Emma é fragmentário, não linear, não apresenta uma "evolução". Destaco outro ponto de consideração importante pensando no trabalho de Emma enquanto Literatura Menor: apesar de ser uma obra subestimada pelos discursos oficiais, estabelece um diálogo com “(...) o conjunto da 
produção cultural em seu tempo" (ibid., p. 120). Ao ler e tomar nota de alguns critérios dos breves procedimentos propostos por Batalha (2014) para trazer o conceito de Literatura Menor e conseguir apontar a obra de Emma Reyes como tal, destaquei alguns pontos relevantes nos quais percebi um diálogo preciso e intenso da obra com a denominação. São estes alguns critérios colocados por Batalha (2014) que associo com a autora:

1) Critério estético: o texto de Emma é certamente desvinculado da noção de um ideal formal, sendo antes agregado à "insuficiência", remete à uma falta, é fragmentário. Temos uma narrativa que nos remonta inteiramente à história oral, uma narrativa que se conta com a fala, boca e língua, uma contação de história. Uma contação de história em que a contadora desabafa até os lapsos que sente. Ilustro:

Você não me corrige e nem sei se o que escrevo é compreensível. Às vezes me parece confuso e não sei se, no conjunto, é possível acompanhar a história. Não tenho cópia, porque escrevo direto, e nem me lembro mais do que escrevi antes. (REYES, 2016, p. 35)

2) Critério sobre o que provoca estranhamento, que denota uma excessiva marginalidade, que mostra uma singularidade particular: uma peculiaridade notável em Memórias por correspondência (2016) é a naturalidade, ou uma tendência a naturalizar processos escatológicos em texto. Temos inúmeros exemplos de conteúdos diretamente relacionados a escatologia nas páginas. Aqui transcrevo um fragmento da carta de:

O da diarreia ia de mal a pior: de repente, sentou numa pedra e declarou que não ia mais prosseguir" (...) "Então, puseram-se a brigar. Um deles puxou uma faca e o da diarreia disse: - Não posso te matar porque preciso cagar. (REYES, 2016, p. 71)

3) Critério decolonial: escritoras de países emergentes, escritoras que usam com propriedade a língua "maior" dos antigos colonizadores, mas fazem um uso da língua assumidamente menor. No caso de Emma, o uso da língua espanhola também constrói uma crítica à colonização da América do Sul, bem como colocar em questão as "heranças" deste trajeto. Temos um exemplo na seguinte passagem:

O novo padre era bem jovem; todas as meninas e as freiras falavam que era muito guapo. Todo dia eu escutava "guapo, guapo". Explicaram-me que significava "bonito". O guapo era de um lugar chamado Espanha, e foi esse pessoal da Espanha que nos trouxe Deus, Maria e todos os santos que tínhamos na capela. (REYES, 2016, p.175)

São nos livros não-canônicos, tal como este aqui trabalhado, que percebemos a diversidade de uma época. Porque os fenômenos de anacronismo e de desatualização de um mesmo momento da cultura são iluminados por estes escritos. O não-canônico tem instrumentos e opera também revelando a luz escondida de muitos momentos históricos (BATALHA, 2014, p. 120). A luz escondida resplandece porque no não-canônico se encerra um verdadeiro potencial explicativo: “(...) parece possível podermos questionar a respeito de certas hierarquias estabelecidas e unificar o nosso olhar sobre um momento da história da literatura, revisitando o acervo do passado sob a ótica do presente" (ibid., p. 120). Neste sentido, Emma é bastante generosa com seus leitores ao oferecer marcadores sociais e institucionais, 
apresentando um texto de denúncia ao modelo de sociedade gerenciada por modelos tradicionalistas advindos e enraizados pelo poder pastoral (Foucault). Também nos descreve os detalhes das normas e das condutas disciplinares que é obrigada a desempenhar durante seu crescimento e constituição de subjetividade, dentro da clausura. É com um relato bastante detalhado que a autora critica, não só a sociedade, mas as instituições fundadoras da América do Sul: "Nesse dia percebi com clareza que no convento (...) a humanidade se divide em classes sociais, e o poder é exclusivo das classes privilegiadas" (REYES, 2016, p. 144).

Figura 2 Les Débuts, Emma Reyes

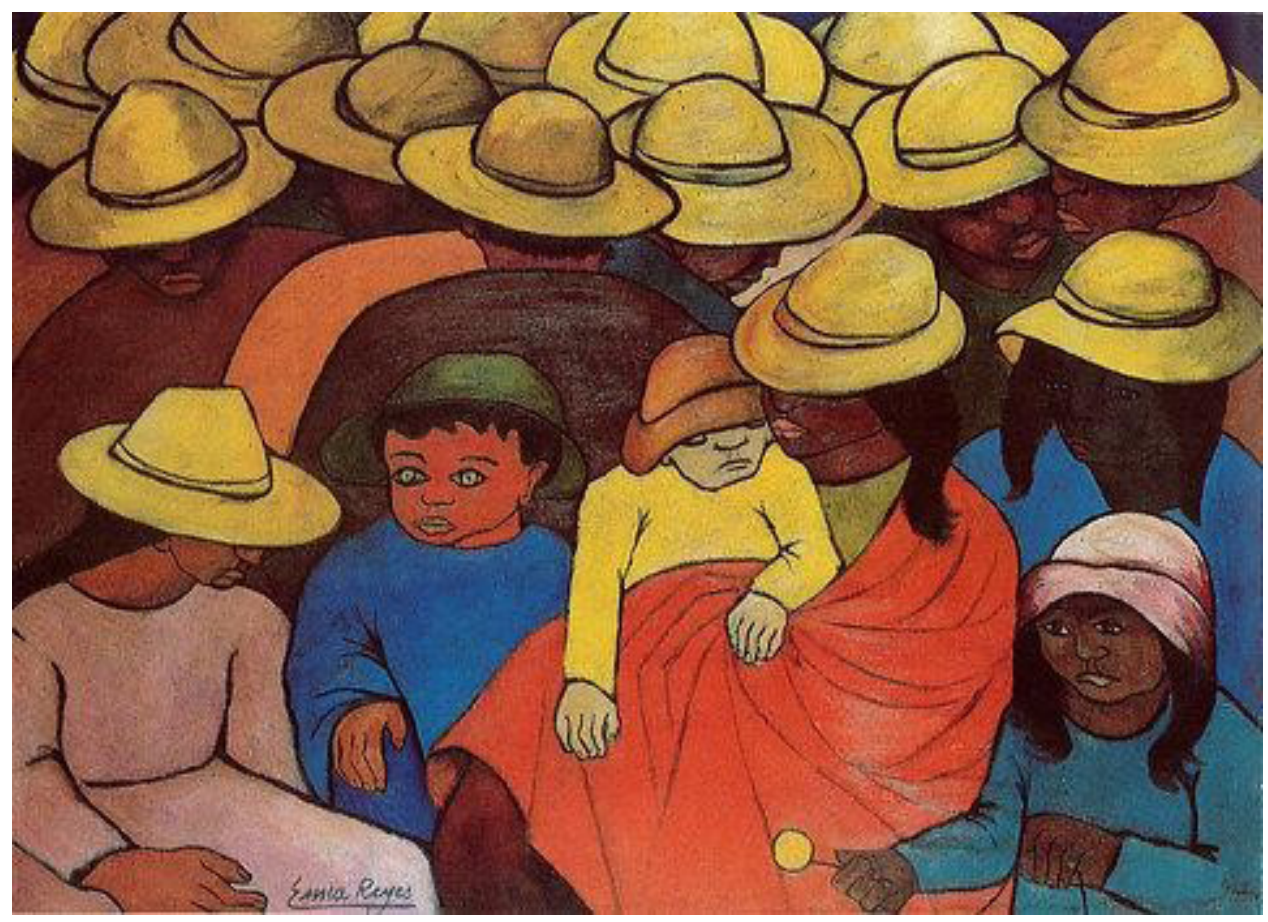

Fonte: http://www.emma-reyes.com/albums/periode-1/. Acesso em 18/05/2020

\section{MEDO E DENÚNCIA}

Nosso único inimigo era o diabo, sabíamos tudo sobre ele; sabíamos mais sobre o diabo do que sobre deus. Conhecíamos todos seus truques, todos os meios de que se valia para nos fazer cair em pecado. Também conhecíamos o inferno de ponta a ponta. Tínhamos a impressão de que poderíamos percorrê-lo de olhos fechados; sabíamos como eram os caldeirões de óleo fervente em que o diabo mergulhava os pecadores nus para, em seguida, arrancar-lhes o couro pedacinho por pedacinho. (...) Sabíamos tudo sobre o diabo, até porque não nos deixavam esquecê-lo. Se jogássemos as linhas fora, as freiras diziam que o diabo ia recolhê-las para nos torturar com elas no inferno, assim como faria com a comida que jogássemos fora. Se confessássemos e comungássemos em pecado, ficaríamos cobertas de chagas imundas, nas quais o diabo depositaria vermes verdes, vermelhos e amarelos que nos devorariam. (REYES, 2016, p. 100-101) 
Nas descrições acima, minuciosamente feitas como se voltasse à infância, como se voltasse a estar ali restrita, no convento, enclausurada; nelas encontramos detalhes, cores, uma narrativa disposta a nos passar os sustos, os medos, a instalação da insegurança na mente destas meninas "pobres". Os relatos que acompanhamos são, principalmente, relatos de temor e medo, de trabalho e insatisfação. Entendemos que a narrativa completa uma intenção de aviso, de denúncia, uma rejeição de um sistema que perpetua relações de poder, que opera historicamente como locomotiva de um estado hierárquico, desigual e opressor. A ferramenta da opressão executada sobre as subalternas é desenvolvida naquelas infâncias pelo medo, como uma manivela "rápida" e eficiente para que houvesse disciplina, ordem, trabalho.

Nossa vida não tinha futuro e toda a nossa ambição era ir do convento direto para o céu, sem passar pelo mundo. No céu nos esperavam de braços abertos e entoando cânticos celestiais, os santos, os anjos, os arcanjos e os querubins, que, entre nuvens, nos conduziriam ao reino de Deus e da Virgem Maria para toda a eternidade. (REYES, 2016, p. 100)

As cartas funcionam como um compêndio de questões sociais gritantes, e o que não passa desapercebido é a angústia e a frustração da autora-personagem com a "instituição Convento", com o poder pastoral instituído e exercido pelas sórores. As relações de poder são intensas e exercidas de modo a manter o funcionamento do maquinário institucional. As cartas dedicadas aos relatos da moradia de Emma nesta "instituição Convento" são onze, e são nestas onze cartas que os esquemas são denunciados, os moldes opressores são verificados. "Fico muito aborrecida ao falar da organização, mas tenho de lhe dar uma ideia real e exata da vida que levávamos" (REYES, 2016, p. 88), confessa Emma à Gérman, após ter escrito: “ (...) o convento não era um orfanato, mas um lugar onde recebiam meninas pobres, com ou sem família, para ensiná-las a trabalhar (...) tudo o que produzíamos com nosso trabalho ia pras feiras, e você pode acreditar que produzíamos alguns milhares de pesos" (ibid., p. 88).

Benelli nos esclarece a definição de instituição total feita por Goffman (1987) como: "Local de residência e de trabalho onde um grande número de indivíduos com situação semelhante, separados da sociedade mais ampla por um período considerável de tempo, levam uma vida fechada e formalmente administrada" (BENELLI, 2002, p. 52). Ele continua, pontuando que um dos modelos de instituições totais podem ser: “(...) estabelecimentos destinados a servir de refúgio do mundo, que também podem servir como locais de instrução para religiosos, tais como: abadias, mosteiros, conventos (ibid., p. 52). Este modelo de instituição fechado por muros tem algumas características que são distintivas: “(...) os indivíduos internados têm, como parte de suas obrigações, uma participação visível (...) nas atividades do estabelecimento" (ibid., p.52). Relata Emma:

A nossa vida estava direcionada a dois únicos e simultâneos objetivos: trabalhar o máximo para ganhar o que comíamos e, segundo as freiras, salvar nossas almas, protegendo-nos do pecado do mundo. Mas o preço que pagávamos para salvar nossas almas eram dez horas de trabalho por dia. (REYES, 2016, p. 98) 
A "Participação obrigatória na atividade da instituição é (...) um símbolo do compromisso e da adesão do indivíduo" (BENELLI, 2002, p. 53). O que é contado nas onze cartas destinadas ao momento de sua vida em uma instituição total, o convento, é o modo de operação entre os muros, o aparato disciplinar que colocava todas as garotas internas em um regime específico de trabalho, que gerava lucro e renda para as freiras e comunidade, e que para elas gerava uma tentativa de garantia em um espaço sagrado: "As freiras falavam do pecado, do diabo, do céu, do inferno, de salvar nossas almas, de ganhar indulgências, de nos arrepender de nossos pecados, de agradecer à Virgem a graça de nos receber na sua casa..." (REYES, 2016, p. 91). Os discursos e práticas se associam aos saberes e poderes, atuando na produção da subjetividade dos atores institucionais. As fases das atividades diárias das internas eram acompanhadas por um grupo grande de pessoas, e, assim como se atua em uma instituição total, todas eram “(...) tratadas da mesma forma e obrigadas a fazer as coisas em conjunto” (BENELLI, 2002, p. 53). Também em uma instituição total, as atividades são estabelecidas de modo rigoroso, em um fazer contínuo, de modo que uma atividade leva a outra e uma sequência de atividades é sobreposta (ibid., p. 53). Há um sistema de regras explícitas pelo grupo dirigente (ibid., p. 53): "Você já percebeu que, com essa infinita variedade de trabalhos, as freiras acabavam encontrando alguma serventia em cada uma de nós (...) Durante meses, passei 10 horas por dia, indo de um ralo para o outro, sem poder sentar nem por um instante" (REYES, 2016, p. 107). Brites esclarece que o aspecto disciplinar, ou seja, que o aparato da disciplina e que o aparato da norma não tiveram dificuldades de se impor porque se integravam nos antigos esquemas e são uma "herança das comunidades monásticas" (BRITES, 2007, p. 174), ou seja, o trabalho executado por Emma e pelas outras garotas dentro do convento estiveram compactuando com um aparato maior, com uma formatação social que previa e executava diversas formas de controle. O controle imposto ali entre os muros conectava-se com o maquinário do Estado, que previa docilizar corpos e disciplinar vidas. Brites argumenta: “(...) já mesmo no séc. XIX as congregações religiosas tinham dado uma preciosa ajuda quando foi necessário utilizar populações rurais na indústria e acostumá-las ao trabalho em oficinas, nas chamadas fábricas-conventos” (ibid., p. 174) e complementa: “(...) para que fosse mais rentável, mais eficiente, mais útil, mais produtivo, o todo teria de ter um efeito superior à soma das forças elementares que o compunham" (ibid., p. 174). Aparece Emma, ilustrando: "Durante o expediente, era estritamente proibido conversar. Só nos permitiam perguntar, em voz baixa, coisas relacionadas ao trabalho. Em cada bastidor ou peça importante, havia uma menina responsável pelo trabalho que dirigia as ajudantes" (REYES, 2016, p. 109). Brites enfatiza que a norma em conjunto com a vigilância, "Tem um poder que obriga à homogeneidade, à existência de um corpo social homogêneo" (2007, p. 176). Acrescento ainda, que o corpo social homogêneo, advindo da norma e da disciplina instaurados duramente pelas superiores, aparece enquanto resultado de uma instituição total, de um híbrido social que se faz "Viveiro ou uma estufa que funciona como instrumento para modelar, mudar e transformar pessoas" (BENELLI, 2002, p. 53). Compreendemos que no Convento desenhado por Emma em palavras, assim como em outros conventos, seminários e monastérios, existe um poder disciplinar predominante em toda sociedade moderna. Este poder é colocado através de tecnologias, técnicas, procedimentos e estratégias produtivas que intencionam o controle, o adestramento e a modelagem dos corpos que estão ali enclausurados. Não se trata de repressão ou de mutilação, antes trata-se de agir sobre estes corpos, produzindo sujeitos e subjetividades dóceis (ibid., p. 66). A disciplina empregada pelas sórores é uma técnica 
de poder que visa fabricar sujeitos, de modo a torná-los otimizados e úteis, corpos submissos que apresentem uma subjetividade docilizada (CANDIOTO, 2012, p. 20). A autora confirma:

Verificava se tínhamos nos penteado, se estávamos de pés limpos (...) e se a bata de ir à missa não estava suja, rasgada ou mal passada (...) Cada uma das freiras tinha um genuflexório e um banco que ficava estrategicamente nos corredores para poder controlar os nossos movimentos e os nossos gestos. (...) (REYES, 2016, p. 95)

"Não podíamos pedir explicação de nada, tudo era pecado e ponto final" (REYES, 2016, p. 100). O retrato da obediência e humildade cristãs confirmados pela narradora tratam-se de uma "Submissão contínua e infinita de um homem a outro, do sujeito a seu pastor" (PRETES; VIANNA, 2014, p. 135). Entendemos na leitura que a religião católica é colocada fora de questionamentos e que a fé é determinada mesmo sem o entendimento prévio das garotas que a recebem. Percebemos o emprego de um poder pastoral, de um poder em que aquele que é dirigido, governado, não obedece necessariamente a uma lei, mas antes, um princípio, objetivando alcançar algo importante para si (ibid., p. 135). No poder pastoral, o rebanho se caracteriza essencialmente pela submissão, pela obediência total e irrestrita da autoridade daquele que o governa (ibid, p. 135). No caso de Emma e de suas colegas, eram empregados o respeito e submissão absoluta às sórores e aos bispos, sem maiores questionamentos. “- Creio, minha filha, que você deve tirar essa ideia da cabeça. Sou eu que estou lhe mandando. Não pense mais nisso" (REYES, 2016, p. 153). Seguindo a lógica do poder pastoral, no convento habitado por Emma era o pastor que sabia o que era " (...) melhor para a salvação de seu rebanho e que caminhos devem seguir para a consecução de tal fim” (PRETES; VIANNA, 2014, p. 135), e ali, cada ovelha deveria aceitar a autoridade do pastor, porque ele representava “ (...) a vontade do próprio Deus" (ibid., p. 136).

A forte narrativa é finalizada com a contextualização de sua percepção das contradições do poder pastoral e institucional ali exercidos. Emma colecionou mais um abuso, desta vez, executado por um padre: "De repente, ele me abraçou pela cintura, empurrou minha cabeça para trás, beijou a minha boca e apertou meus peitos com as duas mãos" (REYES, 2016, p. 179). Neste momento, a jovem fez os cálculos das incoerências que ali permaneciam e, a partir daí, "Tudo relacionado ao convento - as freiras, os padres, Maria e o menino Jesus - me fazia sofrer, e não queria mais ver nada disso" (ibid., p. 180). A autora escolhe terminar a narrativa dissertando críticas ao poder pastoral e à "instituição convento" e, de modo brilhante, relata sua fuga da atmosfera opressora, metaforizando: "Fazia muito tempo que deixara de ser menina. Não havia ninguém na rua além de dois cachorros magros, e um estava cheirando o rabo do outro" (ibid., p.181). Adulta, Emma escreveu. 
Figura 3 P, Emma Reyes

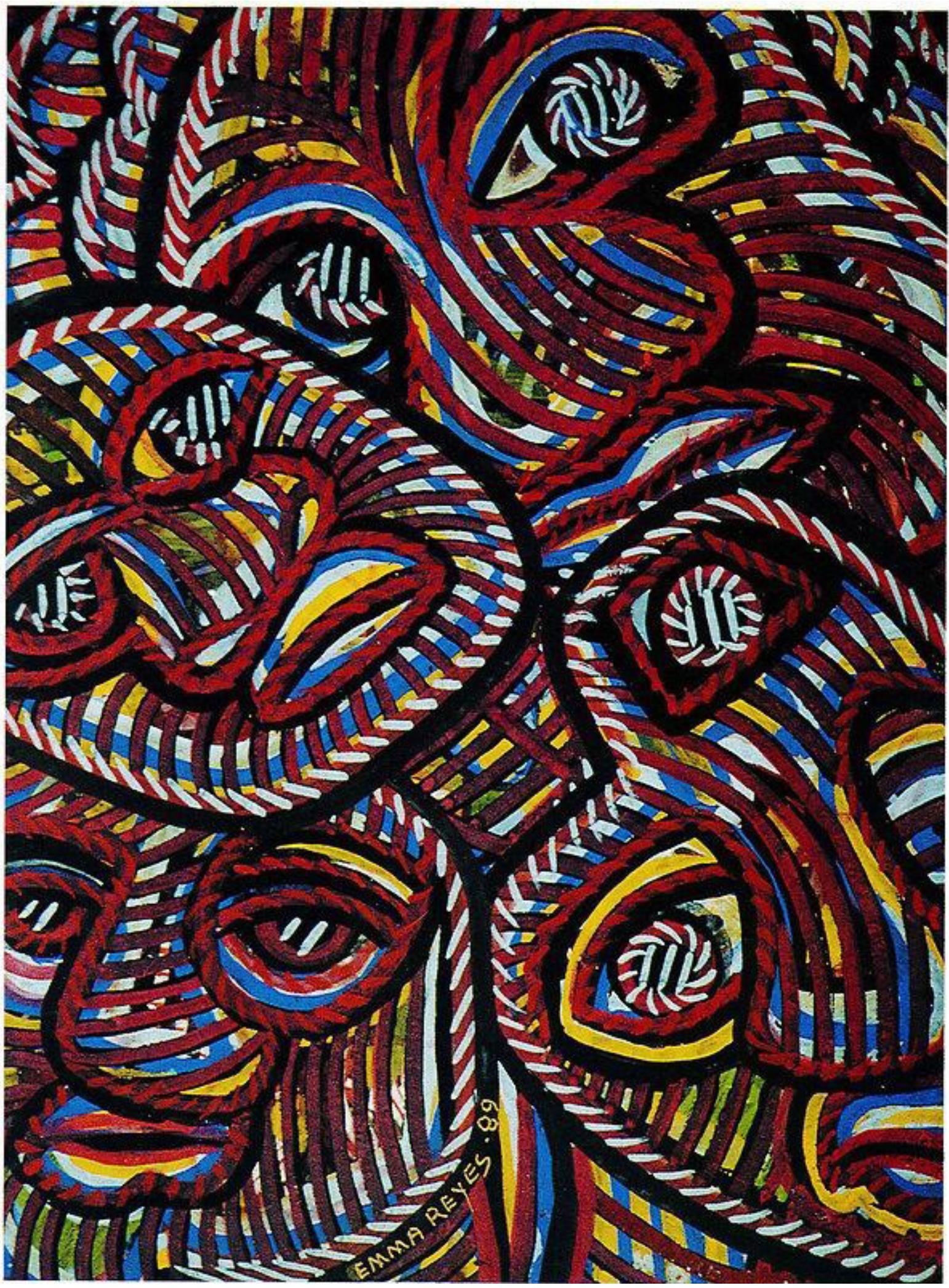

Fonte: http://www.emma-reyes.com/albums/periode-2/content/p/. Acesso em $18 / 05 / 2020$ 


\section{REFERÊNCIAS}

ANTONELlO, D. GONDAR, J. E quando não há fios lógicos? Cad. Psicanál. - CPRJ, Rio de Janeiro, v. 36, n. 30, p. 89-112, jan./jun. 2014

ASSMANN, A. Espaços da recordação: formas e transformações da memória cultural. Trad. de Paulo Soethe (Coord.) Campinas: Editora da Unicamp, 2011.

BATALHA, M. C. O que é uma literatura menor? What is minor literature? Revista Cerrados, vol. 22, n. 35, p. 113-134, 2014.

BENELLI, S. J. Vigiar e punir no manicômio, na prisão e no seminário católico. Revista de Psicologia da UNESP, São Paulo, v. 1, n. 1, p. 51-68, 2002.

BRITES, I. A centralidade de Vigiar e Punir. História da violência nas prisões, na obra de Michel Foucault. Revista Lusófona de Educação, Lisboa, v. 10, n. 10, p. 167-184, 2007.

CANDIOTTO, C. Disciplina e segurança em Michel Foucault: a normalização e a regulação da delinquência. Psicologia \& Sociedade, Belo Horizonte, vol. 24, n. spe., p. 18-24, 2012.

COSTA, L. B. 58 combates para uma política do texto. São Paulo: Lumme Editor, 2017.

DELEUZE, G. GUATTARI, F. Kafka - Para uma literatura menor. 1. ed. São Paulo: Autêntica Editora, 2003.

FREITAS, A. P. SILVEIRA, C.R. MASCIA, M. A. A. O "ser consigo" ao toque do clarim: educação, processos de subjetivação através das "escritas de si”. Revista Eletrônica de Educação. São Carlos, v. 11, n. 2, p. 578-593, 2017

FOSTER, Hal. O retorno do real. Trad. Celia Euvaldo. São Paulo: Cosac-Naify, 2014.

GAGNEBIN, J. M. Lembrar escrever esquecer. São Paulo: Ed. 34, 2006.

HENNIGEN, I. GUARESCHI, N. M. F. A subjetivação na perspectiva dos estudos culturais e foucaultianos. Psicologia da Educação, São Paulo, s/v,

n. 23, p. 57-74, dez. 2006.

IONTA, M. Escrita de si como prática de uma literatura menor: cartas de Anita Malfatti a Mário de Andrade. Estudos Feministas, Florianópolis, v. 19, n. 1, p. 91-101, janeiro-abril/2011

PRETES, E. VIANNA, T. Do pastorado ao governo (bio)político dos homens: notas sobre uma genealogia da governamentabilidade. Revista Epos, Rio de Janeiro, v. 5, n. 1, jan-jun 2014. 
RANCIÉRE, J. Políticas da escrita/ Jacques Ranciére. Trad. Raquel Ramalhete [et al]. Rio de Janeiro: Ed. 34, 1995.

REYES, E. Memória por correspondência. Trad. Hildegard Feist. 1 Ed. São Paulo: Companhia das Letras, 2016.

TEDESCO, S. As práticas do dizer e os processos de subjetivação. Revista Interação em Psicologia, Rio de Janeiro, v. 10, n. 2, p. 357-362, 2006.

Imagens anexadas retiradas de: http://www.emma-reyes.com/albums/

Figura 1 Bram VanVelde, Emma Reyes Fonte: http://www.emma-reyes.com/albums/periode-3/. Acesso em 18/ 05/ 2020 
